Article

\title{
Sodium Levels in Packaged Foods Sold in 14 Latin American and Caribbean Countries: A Food Label Analysis
}

\author{
JoAnne Arcand ${ }^{1}$, Adriana Blanco-Metzler ${ }^{2}{ }^{(1)}$, Karla Benavides Aguilar ${ }^{2}$, Mary R. L'Abbe ${ }^{3}$ and \\ Branka Legetic ${ }^{4, *}$ \\ 1 Faculty of Health Sciences, University of Ontario Institute of Technology 2000 Simcoe St N, Oshawa, \\ ON L1H 7K4, Canada; joanne.arcand@uoit.ca \\ 2 Costa Rican Institute of Research and Training in Nutrition and Health (INCIENSA), Tres Rios Box 4-2250, \\ Costa Rica; ablanco@inciensa.sa.cr (A.B.-M.); kbenavides@inciensa.sa.cr (K.B.A.) \\ 3 Department of Nutritional Sciences, Faculty of Medicine, University of Toronto, Medical Sciences Building, \\ 1 Kings College Circle, Rm 5368, Toronto, ON M5S 1A8, Canada; mary.labbe@utoronto.ca \\ 4 Independent Consultant, Washington, DC 20036, USA \\ * Correspondence: legeticb@gmail.com; Tel.: +1-(202)-492-8629
}

Received: 22 January 2019; Accepted: 2 February 2019; Published: 11 February 2019

\begin{abstract}
Population-wide sodium reduction is a cost-effective approach to address the adverse health effects associated with excess sodium consumption. Latin American and Caribbean (LAC) countries consume excess dietary sodium. Packaged foods are a major contributor to sodium intake and a target for sodium reduction interventions. This study examined sodium levels in 12 categories of packaged foods sold in 14 LAC ( $n=16,357)$. Mean sodium levels and percentiles were examined. Sodium levels were compared to regional sodium reduction targets. In this baseline analysis, $82 \%$ of foods met the regional target and $47 \%$ met the lower target. The greatest proportion of products meeting the regional target were uncooked pasta and noodles (98\%), flavored cookies/crackers (97\%), seasonings for sides / main dishes (96\%), mayonnaise (94\%), and cured/preserved meats (91\%). A large proportion of foods met the lower target among uncooked pasta and noodles $(88 \%)$, cooked pasta and noodles $(88 \%)$, and meat/fish seasonings $(88 \%)$. The highest the highest median sodium levels were among condiments $(7778 \mathrm{mg} / 100 \mathrm{~g})$, processed meats $(870 \mathrm{mg} / 100 \mathrm{~g})$, mayonnaise $(755 \mathrm{mg} / 100 \mathrm{~g})$, bread products $(458 \mathrm{mg} / 100 \mathrm{~g})$, cheese $(643 \mathrm{mg} / 100 \mathrm{~g})$, and snack foods (625 mg/100 g). These baseline data suggest that sodium reduction targets may need to be more stringent to enable effective lowering of sodium intake.
\end{abstract}

Keywords: sodium; sodium reduction; sodium targets; food supply; food policy; public health; global health

\section{Introduction}

Hypertension prevention and control in Latin American and Caribbean (LAC) countries is a priority action area for the World Health Organization (WHO) and Pan-American Health Organization (PAHO) to reduce the burden of cardiovascular disease and stroke. The current goal is to reduce hypertension prevalence to $35 \%$ by 2019 [1]. Hypertension is a major risk factor for cardiovascular disease (CVD) and accounts for nearly 1 in 5 deaths in LAC, with prevalence rates in many countries exceeding one-third of adults [2]. These rates are among the highest in the world.

Excess dietary sodium (salt) is a significant causal risk factor in the development of hypertension and is associated with cardiovascular and stroke morbidity and mortality [3-5]. To reduce the health burden associated with excess sodium intake, the WHO set a global target of reducing dietary 
salt intake by $30 \%$ by 2025 [6]. Worldwide, most developed countries consume excess sodium compared to the WHO's recommended intake of $2000 \mathrm{mg}$ sodium (5 g salt) per day [7]. Sodium intake in LAC is also high. For example, estimated sodium intake is $4407 \mathrm{mg}$ (11.2 g salt)/day in Argentina [8,9], $4700 \mathrm{mg} /$ day (12g salt/day) in Brazil [10], $4600 \mathrm{mg} /$ day (11.5 g salt/day) in Costa Rica [11], and $7970 \mathrm{mg} /$ day (19.9 g salt/day) in Colombia [12]. In Argentina, $65 \%$ to $70 \%$ of dietary sodium is derived from processed foods, with $25 \%$ from bread [13]. In Brazil, French bread (artisanal), soups, dairy and meat products are responsible for over $90 \%$ of sodium from processed foods [14], although more sodium comes from added salt and condiments. Over time, Costa Rica has seen a significant $15 \%$ increase in sodium intake, which is largely attributed to the higher intake of condiments and other processed foods [11]. In Costa Rica, income level was inversely related to sodium availability [11]. Data from Columbia show that 96 single food items contributed $72 \%$ of total dietary sodium in Colombians' diet, with the most dietary sodium coming from bakery products (30.5\%) [15]. Similar data and trends in sodium intake are found throughout the LAC region.

To facilitate the reduction and monitoring of sodium levels in foods produced and sold in LAC, regional sodium reduction targets were set for 12 categories (18 subcategories) of packaged foods that were commonly sold and consumed in LAC in 2015 [16]. These targets were adopted by the Salt Smart Consortium-a group of government, industry, and non-governmental organization stakeholders-in January 2015. The targets included a regional target (maximum) level and a lower target level, which were set at sodium reduction target levels similar to other jurisdictions. To date, there have been no studies examining sodium levels across LAC [16]. The purpose of this study was to conduct a cross-sectional examination of sodium levels in packaged foods sold in 14 LAC countries and determine the proportion of these foods that meet or exceed the 2015 established sodium reduction targets. This data will serve as critical baseline information that will be used for longitudinal monitoring of sodium levels in the food supply in LAC countries.

\section{Materials and Methods}

\subsection{Study Design, Participants, and Data Collection}

This cross-sectional survey was conducted between July 2015 and February 2016 in 14 participating countries: Argentina, Barbados, Brazil, Chile, Costa Rica, Cuba, Ecuador, Guatemala, Jamaica, Mexico, Paraguay, Panama, Peru, and Trinidad and Tobago.

Participating country research teams led by the presidents of the national branches of the Latin American Network of Food Composition Data Systems (LATINFOODS), who have expertise and experience in food composition, were trained to collect data on and develop a database of foods pertaining to the 12 food categories that comprise the regional sodium reduction targets. Data were collected according to a protocol that was established and approved by the PAHO/WHO Technical Advisory Group on Cardiovascular Diseases Prevention through Population-Wide Dietary Salt Reduction. Data on packaged foods was acquired by systematically capturing information on foods sold in grocery stores. The nutrition facts table data were recorded and photos of each food package were taken and stored. Grocery stores that had the greatest market share in each country were selected. Each country was required to collect a minimum number of samples for each food category: breads $(n \geq 100)$, soups $(n \geq 80)$, mayonnaise $(n \geq 30)$, cookies and biscuits $(n \geq 150)$, cakes $(n \geq 150)$, meat (i.e., sausages, cured meats, breaded meat) $(n \geq 200)$, breakfast cereals $(n \geq 100)$, dairy $(n \geq 150)$, butter and dairy spreads $(n \geq 50)$, snacks $(n \geq 200)$, pasta $(n \geq 50)$, and seasonings $(n \geq 100)$.

Data captured from each food packaged included the following: product name, number of servings per package, serving size, levels of nutrients on the nutrition facts table or equivalent (sodium, calories, sugar, etc.) per serving or per $100 \mathrm{~g}$ or both, as well as the presence of front of package information such as logos and claims. Where foods required nutrition information to be presented "as consumed," the LATINFOODS database was used to create recipes (http:/ /inta.cl/latinfoods/default). Specifically, recipes were required for the wet and dry soups and noodles in broth. This was a 
necessary step to ensure like-foods sold in different forms could be compared within the same food category (i.e., a soup fully prepared could be compared with a soup sold as a condensed product) when presented in a standardized format $(\mathrm{mg} / 100 \mathrm{~g})$. Once all data was entered, quality assurance measures were implemented. This included duplicate review and entry of food categories to ensure accurate classification, as well as ranking foods from highest to lowest sodium values $(\mathrm{mg} / \mathrm{serving}$ and $\mathrm{mg} / 100 \mathrm{~g}$ ) to identify errors in typography, classification, or in recipes.

\subsection{Analysis of Sodium Levels}

Foods were classified into the food group categories established by the regional sodium reduction targets, which include major subcategories and minor subcategories [16]. The sodium content in foods was obtained from the nutrition facts table ( $\mathrm{mg} /$ serving) and was converted to standardized units $(\mathrm{mg} / 100 \mathrm{~g})$. Means and standard deviations were calculated, as well as the 10th, 25th, 50th, and 75th percentiles and minimum and maximum levels. Standardized units $(\mathrm{mg} / 100 \mathrm{~g})$ were used to determine the proportion of products that met or exceeded the regional sodium target levels: the regional target level and the lower target level. Cheese was excluded from this analysis $(n=1911)$ since this food category does not have a sodium reduction target level. Continuous variables are presented as the mean \pm standard deviation. Categorical variables are presented as frequency (percent).

\section{Results}

\subsection{Mean Sodium Levels}

This analysis included 16,357 foods across 12 major food categories and from 14 countries (Table S1). Overall, the highest median sodium levels per $100 \mathrm{~g}$ were among condiments $(7778 \mathrm{mg} / 100 \mathrm{~g}$, range: 0 to $51,670 \mathrm{mg} / 100 \mathrm{~g}$ ), processed meats $(870 \mathrm{mg} / 100 \mathrm{~g}$, range: 389 to $7000 \mathrm{mg} / 100 \mathrm{~g}$ ), mayonnaise $(755 \mathrm{mg} / 100 \mathrm{~g}$, range 470 to $4000 \mathrm{mg} / 100 \mathrm{~g}$ ), bread products (458 mg/100 g, range: 190 to $4444 \mathrm{mg} / 100 \mathrm{~g})$, cheese $(643 \mathrm{mg} / 100 \mathrm{~g}$, range: 274 to $14,740 \mathrm{mg} / 100 \mathrm{~g}$ ), and snack foods ( $625 \mathrm{mg} / 100 \mathrm{~g}$, range 211 to $42,860 \mathrm{mg} / 100 \mathrm{~g}$ ) (Table 1). This data varied from country to country (Tables S2 and S3). Overall, there was substantive variability in sodium levels observed within certain food categories: condiments ( 0 to $51,670 \mathrm{mg} / 100 \mathrm{~g}$ ), snack foods ( 0 to $42,860 \mathrm{mg} / 100 \mathrm{~g}$ ), and cheeses (0 to $14,740 \mathrm{mg} / 100 \mathrm{~g}$ ).

Table 1. Overall levels of sodium in packaged foods by food category.

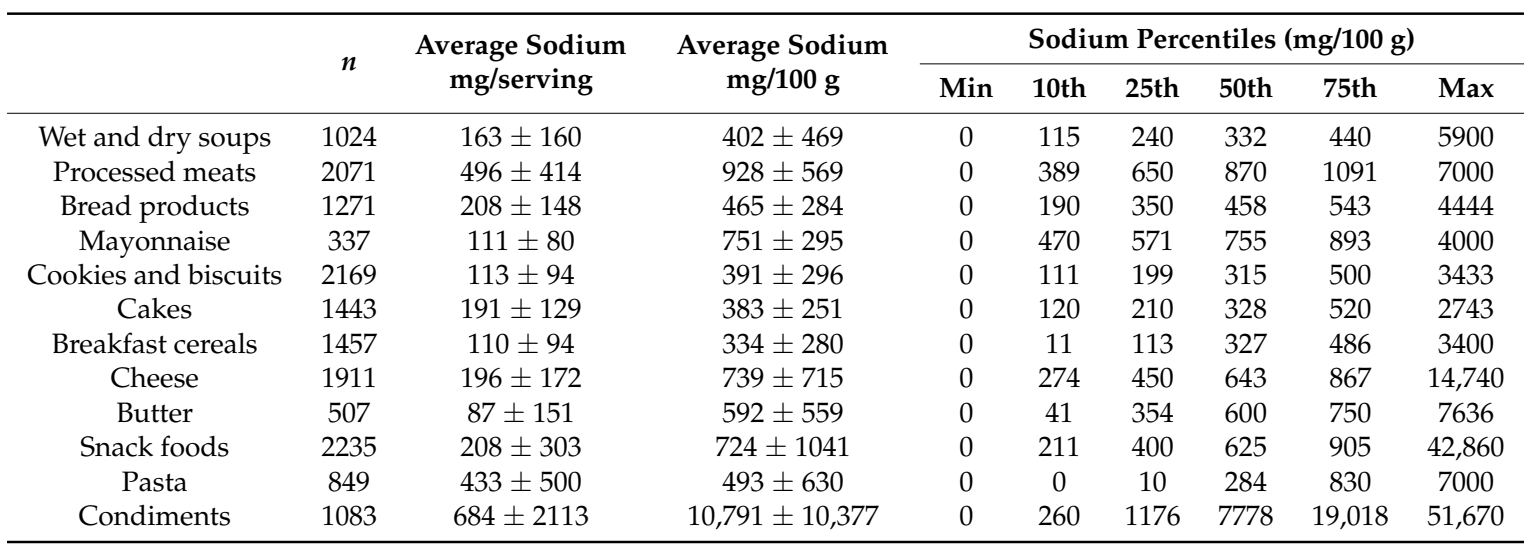

Data presented as mean \pm standard deviation.

On examination of median levels across countries, high between-country variation was observed within food categories: condiments (434 mg/100 g in Cuba to 19,600 mg/100 g in Paraguay), pasta ( $2 \mathrm{mg} / 100 \mathrm{~g}$ in Cuba to $1651 \mathrm{mg} / 100 \mathrm{~g}$ in Brazil), butter $(120 \mathrm{mg} / 100 \mathrm{~g}$ in Argentina to $786 \mathrm{mg} / 100 \mathrm{~g}$ in Peru), cheese (482 mg/100 g in Chile to $1146 \mathrm{mg} / 100 \mathrm{~g}$ in Ecuador), cookies and biscuits (183 mg/100 g in Chile to $677 \mathrm{mg} / 100 \mathrm{~g}$ in Peru), cakes (183 mg/100 g in Chile to $677 \mathrm{mg} / 100 \mathrm{~g}$ in Peru), mayonnaise 
(531 mg/100 g in Cuba to $975 \mathrm{mg} / 100 \mathrm{~g}$ in Brazil), and soups (94 mg/100 g in Cuba to $533 \mathrm{mg} / 100 \mathrm{~g}$ in Ecuador). However, a low to moderate level of between-country variation in sodium levels was observed for other food categories such as bread (410 mg/100 $\mathrm{g}$ in Barbados to $528 \mathrm{mg} / 100 \mathrm{~g}$ in Cuba), snack foods (458 mg/100 g in Chile to $764 \mathrm{mg} / 100 \mathrm{~g}$ in Brazil), processed meats $(720 \mathrm{mg} / 100 \mathrm{~g}$ in Panama to $1035 \mathrm{mg} / 100 \mathrm{~g}$ in Brazil), and breakfast cereals (125 mg/100 g in Paraguay to $475 \mathrm{mg} / 100 \mathrm{~g}$ in Jamaica).

\subsection{Proportion of Foods Meeting the Sodium Targets}

Overall, across all countries and food categories, $82 \%$ of packaged foods met the regional target level and $47 \%$ met the lower target level. The greatest proportion of products meeting the regional target level was among uncooked noodles and pasta (98\%), flavored cookies and crackers $(97 \%)$, seasonings for sides and main dishes (96\%), mayonnaise (94\%), and cured and preserved meats $(91 \%)$ (Table 2). The lowest proportion of foods meeting the regional targets were wet and dry soups (59\%), bouillon cubes and powders (62\%), cakes $(64 \%)$, and breaded meat and poultry $(65 \%)$. A few food categories had a large proportion of products meeting the lower target level: pasta and noodles, uncooked $(88 \%)$, pasta and noodles, cooked $(88 \%)$, and meat and fish seasonings $(88 \%)$. However, several food categories had fewer products meeting the lower target: meats and sausages (25\%), cakes $(25 \%)$, breaded meat and poultry $(28 \%)$, bread $(34 \%)$, bouillon cubes and powders $(37 \%)$, butter $(37 \%)$, mayonnaise (38\%), and snack foods (39\%).

Table 2. Summary of the proportion of foods meeting the regional sodium reduction targets by food category.

\begin{tabular}{ccccc}
\hline & $\boldsymbol{n}$ & $\begin{array}{c}\text { \% Meeting } \\
\text { Regional Target } \\
\boldsymbol{n} \mathbf{( \% )}\end{array}$ & $\begin{array}{c}\text { \% Exceeding } \\
\text { Regional Target } \\
\boldsymbol{n} \mathbf{( \% )}\end{array}$ & $\begin{array}{c}\text { \% Meeting Lower } \\
\text { Target } \\
\boldsymbol{n}(\mathbf{\%})\end{array}$ \\
\hline Overall & 14,446 & $11,868(82)$ & $2578(18)$ & $6819(47)$ \\
Wet and dry soups & 817 & $485(59)$ & $332(41)$ & $353(43)$ \\
Noodles in broth & 207 & $169(82)$ & $38(18)$ & $114(55)$ \\
Meats and sausages & 1535 & $1329(87)$ & $206(13)$ & $378(25)$ \\
Cured and preserved meats & 320 & $290(91)$ & $30(9)$ & $213(67)$ \\
Breaded meat and poultry & 216 & $141(65)$ & $75(35)$ & $60(28)$ \\
Bread products & 1271 & $1053(83)$ & $218(17)$ & $434(34)$ \\
Mayonnaise & 337 & $317(94)$ & $20(6)$ & $128(38)$ \\
Cookies and sweet cookies & 1560 & $1406(90)$ & $154(10)$ & $750(48)$ \\
Flavored cookies and crackers & 609 & $591(97)$ & $18(3)$ & $362(59)$ \\
Cakes & 1443 & $919(64)$ & $524(36)$ & $356(25)$ \\
Breakfast cereals & 1457 & $1326(91)$ & $131(9)$ & $114(76)$ \\
Butter & 507 & $428(84)$ & $79(16)$ & $186(37)$ \\
Snacks & 2235 & $1674(75)$ & $561(25)$ & $865(39)$ \\
Pasta and noodles, uncooked & 696 & $681(98)$ & $15(2)$ & $609(88)$ \\
Pasta and noodles, as consumed & 153 & $140(92)$ & $13(8)$ & $134(88)$ \\
Seasonings for side and main dishes & 390 & $375(96)$ & $15(4)$ & $286(73)$ \\
Meat and fish seasonings & 435 & $385(89)$ & $50(11)$ & $381(86)$ \\
Bouillon cubes and powders & 258 & $159(62)$ & $99(38)$ & $96(37)$ \\
\hline
\end{tabular}

Data presented as $n(\%)$. Wet and dry soups, noodles and broth and bouillon cubes and powders are all presented "as consumed."

All countries had more than three-quarters of products meeting the target levels (Table 3 ). Two countries had $>90 \%$ of food products meeting the regional targets, which included Chile $(92 \%)$ and Cuba (90\%). Countries with the lowest proportion of products meeting the regional targets were Brazil $(77 \%)$, Costa Rica $(77 \%)$, Guatemala $(78 \%)$ and Trinidad and Tobago $(79 \%)$. For five countries, more than half of food products contained sodium levels below the lower target: Cuba (59\%), Peru (56\%), Chile (55\%), Paraguay (55\%), and Ecuador (51\%). 
Table 3. Summary of the proportion of products meeting or exceeding the regional sodium reduction targets by country.

\begin{tabular}{ccccc}
\hline & $\boldsymbol{n}$ & $\begin{array}{c}\text { \% Meeting } \\
\text { Regional Target } \\
\boldsymbol{n} \mathbf{( \% )}\end{array}$ & $\begin{array}{c}\text { \% Exceeding } \\
\text { Regional Target } \\
\boldsymbol{n} \mathbf{( \% )}\end{array}$ & $\begin{array}{c}\text { \% Meeting Lower } \\
\text { Target } \\
\boldsymbol{n} \mathbf{( \% )}\end{array}$ \\
\hline Overall & 14,382 & $11,868(82)$ & $2578(18)$ & $6819(47)$ \\
Argentina & 1125 & $940(84)$ & $185(16)$ & $508(45)$ \\
Barbados & 1201 & $979(82)$ & $220(18)$ & $496(41)$ \\
Brazil & 1224 & $944(77)$ & $280(23)$ & $483(39)$ \\
Chile & 1178 & $1087(92)$ & $91(8)$ & $652(55)$ \\
Costa Rica & 1086 & $834(77)$ & $252(23)$ & $460(43)$ \\
Cuba & 209 & $188(90)$ & $21(10)$ & $124(59)$ \\
Ecuador & 1177 & $976(83)$ & $201(17)$ & $604(51)$ \\
Guatemala & 944 & $734(78)$ & $207(22)$ & $430(46)$ \\
Jamaica & 907 & $731(81)$ & $176(19)$ & $399(44)$ \\
Mexico & 1267 & $1043(82)$ & $224(18)$ & $588(46)$ \\
Panama & 1339 & $1089(81)$ & $250(19)$ & $607(45)$ \\
Paraguay & 871 & $756(87)$ & $115(13)$ & $482(55)$ \\
Peru & 777 & $668(86)$ & $109(14)$ & $434(56)$ \\
Trinidad and Tobago & 1141 & $899(79)$ & $242(21 \%)$ & $542(48)$ \\
\hline
\end{tabular}

Data presented as $n(\%)$.

On examination of country-level data within individual food categories, some food categories had significant variation between countries in relation to the proportion of products that met the regional targets, while others did not (Table S4). For example, significant between-country variation was observed among breaded meat and poultry (range: $17 \%$ to $100 \%$ ), noodles in broth (range: $25 \%$ to $100 \%$ ), cakes (range: $31 \%$ to $100 \%$ ), wet and dry soups (range: $18 \%$ to $81 \%$ ), and bouillon cubes and powders (range: $33 \%$ to $93 \%$ ). In contrast, a lower level of between-country variability was observed among pasta and noodles, uncooked (range: $94 \%$ to $100 \%$ ), flavored cookies and crackers (range: $88 \%$ to $100 \%$ ), mayonnaise (range: $86 \%$ to $100 \%$ ), and breakfast cereals (range: $82 \%$ to $99 \%$ ). Within-country variations were also observed in the proportion of foods meeting the sodium targets across food categories (Table S5).

\section{Discussion}

This is the first known comprehensive assessment of sodium levels in packaged foods sold in LAC countries. Although there was significant between-country variation in the mean sodium content of packaged foods across food categories, in 2015 an overwhelming proportion of packaged foods $(83 \%)$ at baseline were already meeting the regional targets and approximately half of the foods met the lower target. Importantly, these are baseline data that will be used for longitudinal assessments of sodium in the food supply. These data may also be used to inform the revision of targets and timelines for sodium reduction in the region.

While sodium added through table salt or seasonings remains a significant source of dietary sodium in some LAC countries, the consumption of packaged and prepared foods is increasing [11,17]. This places significant importance on food supply interventions aimed at limiting or reducing the amount of sodium added to packaged and prepared foods; emphasizing the need for sodium reduction targets. The harmonized regional sodium targets were adopted by members of the PAHO-led Salt Smart Consortium in January 2015 [16]. The Consortium included a group of health, governmental, non-governmental, industry, and academic stakeholders from countries in the Americas. The intention of the harmonized targets was to provide a guideline for countries who do not yet have targets or timelines in place and to ensure regional food manufacturers have consistent reformulation goals, all for the benefit of reducing the population's sodium intake. The harmonized targets were developed considering existing targets and timelines set in Argentina, Brazil, Canada, Chile, and the United 
Kingdom. The maximum level (mg/100 g), or upper limit, set by these countries was used to establish the regional target level. Where the regional target (maximum) level has been met, food manufacturers are encouraged to reformulate to the lower target level. The lower target level is an agreed upon level that is reflective of the average target levels in the reference countries; albeit, many of the regional lower target levels set slightly higher.

These data have similarities and differences compared to other baseline sodium assessments, which has important implications for the re-evaluation of sodium targets and timelines for the region. For example, in a baseline assessment of Canadian packaged foods, $25 \%$ of foods exceeded the maximum level $[18,19]$, whereas $27 \%$ of foods in the current study exceeded the comparable regional target (maximum) level. However, baseline data in Canada showed that only $29 \%$ of foods met the sodium target goal level (Phase 3 level), while in the current analysis almost half (47\%) of foods met the comparable lower target (goal) level. In this study, several key food categories, contributing a high proportion of dietary sodium (e.g., bread, meats and sausages, breaded meat and poultry), had fewer than one-third of products meet the lower target level. However, several food categories had more than half of food products already meeting the lower target including noodles in broth, cured and preserved meats, flavored cookies and crackers, breakfast cereals, pasta (cooked and uncooked), and meat/fish seasonings.

Given that the population's sodium intake far exceeds recommendations in LAC, the data in this study point to the need for more stringent lower target levels to effectively achieve population-wide sodium reduction goals. In their report published in January 2015, the PAHO-led Salt Smart Consortium indicated a re-assessment of the targets every two years, in 2016 and 2018 and again in 2020. This is consistent with the approach taken by the United Kingdom [20]. To date, no known re-assessment of the targets has occurred. These data provide critical information that can be used in the evaluation and re-assessment of the sodium targets and timelines. In one published paper, the authors recommended that the maximum sodium target (i.e., regional level target) be based on the 70th percentile of products in a food category [21]. In Canada's initial set of targets, which used sales-weighted averages for sodium in food categories, sodium reduction target levels were set at the 25th to 30th percentile while the maximum level was set at the 75th percentile [22].

At the time of data collection, there was regional between-country variance in regulatory approaches to reducing the sodium content of prepared and packaged food. Countries such as Brazil, Costa Rica, and Chile were working with the food industry to voluntarily reduce sodium levels in packaged foods. Countries such as Argentina and Paraguay have a mixed approach, with voluntary limits for many food categories and regulated limits on the sodium content of key foods such as bread products [23]. Longitudinal data on the sodium content of foods will allow for the analysis and comparisons of different regulatory approaches on changes to the sodium content of foods, on population sodium intake and on subsequent health outcomes. Such an analysis is needed since by 2017 more than 20 countries in the LAC region had national sodium reduction strategies with 12/20 countries having national level programs to address the sodium content of foods [24]. Additionally, many of these low- and middle-income countries have a high burden of hypertension and cardiovascular diseases; thus, a profound health and economic impact would be expected from implementing effective strategies that lower population sodium intake.

It is important to discuss limitations of this study. Not every country collected the required sample size for each food category. However, data were systematically collected, and the smaller sample sizes reflect product availability in the market. Data in this study were also not sales-weighted. Sales-weighted averages would be considered ideal in assessing the relative contribution a product contributes to sodium levels based on market sales. However, such data is expensive, making it inaccessible, and is not available in all of the countries included in this study. The adopted harmonized targets also do not use sales-weighted averages; thus the analyses in this study are most appropriate. Finally, this analysis relied on nutrition information on the nutrition facts table. Regulations on the presence and variance of data on the nutrition facts table information vary across countries. In some 
countries, regulations permit up to $20 \%$ variance on values reported on the label, compared to the actual sodium content of foods. While the majority of foods have been found to comply with these regulatory requirements, a small proportion of foods may not [25]. This should be considered when interpreting the findings. Importantly, however, this data has been used in other research studies to monitor change over time and is currently the only data available to conduct surveillance activities.

\section{Conclusions}

In summary, these data provide a baseline assessment of sodium levels in packaged foods sold in LAC. A relatively high proportion of foods in the baseline analysis was already meeting the regional target levels, suggesting that targets in some food categories need to be made more stringent to enable effective lowering of population sodium intake. With longitudinal updating of this data, as part of a grant funding from the International Development Research Centre and PAHO, progress on sodium reformulation and subsequent reduction in population sodium intake and improved health outcomes can be tracked over time.

Supplementary Materials: The following are available online at http:/ /www.mdpi.com/2072-6643/11/2/369/s1, Table S1: Number of packaged foods by food category and by country. Table S2: Detailed assessment of sodium levels in packaged foods by food category. Table S3: Detailed assessment sodium levels in packaged foods by country. Table S4: Detailed assessment of the proportion of foods meeting the regional sodium reduction targets by food category. Table S5: Detailed assessment of the proportion of foods meeting the regional sodium targets by country.

Author Contributions: J.A. informed data analysis and interpretation and prepared the manuscript; K.B.A. participated in data collection and analysis and critically reviewed the manuscript. A.B.-M., M.R.L., and B.L. informed the study design, analysis and interpretation, and critically reviewed the manuscript.

Funding: This was supported by funding from the Pan American Health Organization and in-kind contributions from participating countries.

Acknowledgments: The authors wish to thank the significant contributions of the following individuals and their research teams who have contributed towards data collection and quality assurance: Norma Samman (Argentina), Rachel Harris (Barbados), Fernanda Grande (Brazil), Lilia Masson (Chile), José Luis Rodríguez (Cuba), Johana Ortiz U. (Ecuador), Ana Victoria Roman (Guatemala), Audrey Morris (Jamaica), Maricruz Morales Zarate (Mexico), Leticia Núñez (Panama), Felicia Canete (Paraguay), María Reyes García (Peru), and June Holdip (Trinidad and Tobago) for their contributions to data collection and analysis. The authors also wish to thank Olayinka Sanusi for her administrative assistance in preparing the data tables and manuscript.

Conflicts of Interest: The authors have no conflicts of interest to declare.

\section{References}

1. Pan American Health Organization. 53rd Directing Council. 66th Session of the Regional Committee of WHO for the Americas; Strategic Plan of the Pan American Health Organization: Washington, DC, USA, 2014.

2. Kearney, P.M.; Whelton, P.K.; Whelton, M.; Reynolds, K.; Muntner, P.; He, J. Global burden of hypertension: Analysis of worldwide data. Lancet 2005, 365, 217-223. [CrossRef]

3. Bibbins-Domingo, K.; Chertow, G.M.; Coxson, P.G.; Moran, A.; Lightwood, J.M.; Pletcher, M.J.; Goldman, L. Projected effect of dietary salt reductions on future cardiovascular disease. N. Engl. J. Med. 2010, 362, 590-599. [CrossRef] [PubMed]

4. Joffres, M.R.; Campbell, N.R.; Manns, B.; Tu, K. Estimate of the benefits of a population-based reduction in dietary sodium additives on hypertension and its related health care costs in Canada. Can. J. Cardiol. 2007, 23, 437-443. [CrossRef]

5. Aburto, N.J.; Ziolkovska, A.; Hooper, L.; Elliott, P.; Cappuccio, F.P.; Meerpohl, J.J. Effect of lower sodium intake on health: Systematic review and meta-analyses. BMJ 2013, 346, f1326. [CrossRef] [PubMed]

6. World Health Organization. Formal Meeting of Member States to Conclude the Work on the Comprehensive Global Monitoring Framework, Including Indicators, and a Set of Voluntary Global Targets for the Prevention and Control of Noncommunicable Diseases; World Health Organization: Geneva, Switzerland, 2012.

7. World Health Organization. Guideline: Sodium Intake for Adults and Children; World Health Organization: Geneva, Switzerland, 2012. 
8. Elorriaga, N.; Gutierrez, L.; Romero, I.B.; Moyano, D.L.; Poggio, R.; Calandrelli, M.; Mores, N.; Rubinstein, A.; Irazola, $\mathrm{V}$. Collecting evidence to inform salt reduction policies in argentina: identifying sources of sodium intake in adults from a population-based sample. Nutrients 2017, 9, 964. [CrossRef] [PubMed]

9. Ministerio de Salud de la Nación. Estrategia Piloto Para Reducir el Consumo de Sal en la Provincia de la Pampa; Ministerio de Salud de la Nación: Buenos Aires, Argentina, 2013.

10. Sarno, F.; Claro, R.M.; Levy, R.B.; Bandoni, D.H.; Monteiro, C.A. Estimated sodium intake for the Brazilian population, 2008-2009. Rev. Saude Publica 2013, 47, 571-578. [CrossRef] [PubMed]

11. Blanco-Metzler, A.; Moreira Claro, R.; Heredia-Blonval, K.; Caravaca Rodríguez, I.; Montero-Campos, M.; Legetic, B.; L'Abbe, M. Baseline and estimated trends of sodium availability and food sources in the Costa Rican population during 2004-2005 and 2012-2013. Nutrients 2017, 9, 1020. [CrossRef] [PubMed]

12. Ruiz, H.; Jiménez, G. Prevalencia de los Desordenes por Deficiencia de yodo e Ingestión Promedio de sal Colombia, 1994-1998; Ministerio de Salud: Bogotá, Colombia, 2001.

13. Ferrante, D.; Apro, N.; Ferreira, V.; Virgolini, M.; Aguilar, V.; Sosa, M.; Perel, P.; Casas, J. Feasibility of salt reduction in processed foods in Argentina. Revista Panam. Salud Publica 2011, 29, 69-75. [CrossRef]

14. Nilson, E.A.F.; Spaniol, A.M.; Goncalves, V.S.S.; Moura, I.; Silva, S.A.; L'Abbe, M.; Jaime, P.C. Sodium reduction in processed foods in brazil: analysis of food categories and voluntary targets from 2011 to 2017. Nutrients 2017, 9, 742. [CrossRef] [PubMed]

15. Gaitan, D.; Estrada, A.; Lozano, G.; Correa, L. Food sources of sodium: Analysis based on a national survey in Colombia. Nutricion Hospitalaria 2015, 32, 2338-2345.

16. Pan American Health Organization. Saltsmart Consortium Consensus Statement to Advance Target Harmonization by Agreeing on Regional Targets for the Salt/Sodium Content of Key Food Categories. Available online: https://www.paho.org/hq/dmdocuments/2015/consensus-statement--targets.pdf (accessed on 1 December 2018).

17. Monteiro, C.A.; Levy, R.B.; Claro, R.M.; de Castro, I.R.R.; Cannon, G. Increasing consumption of ultra-processed foods and likely impact on human health: Evidence from Brazil. Public Health Nutr. 2010, 14, 5-13. [CrossRef] [PubMed]

18. Arcand, J.; Au, J.T.; Schermel, A.; L'Abbe, M.R. A comprehensive analysis of sodium levels in the Canadian packaged food supply. Am. J. Prev. Med. 2014, 46, 633-642. [CrossRef] [PubMed]

19. Arcand, J.; Jefferson, K.; Schermel, A.; Shah, F.; Trang, S.; Kutlesa, D.; Lou, W.; L'Abbe, M.R. Examination of food industry progress in reducing the sodium content of packaged foods in Canada: 2010 to 2013. Appl. Physiol. Nutr. Metab. 2016, 41, 684-690. [CrossRef] [PubMed]

20. Public Health England. Salt Reduction Targets for 2017; Public Health England: London, UK, 2017.

21. Campbell, N.; Legowski, B.; Legetic, B.; Ferrante, D.; Nilson, E.; Campbell, C.; L'Abbé, M. Targets and timelines for reducing salt in processed food in the Americas. J. Clin. Hypertens. 2014, 16, 619-623. [CrossRef] [PubMed]

22. Health Canada. Guidance for the Food Industry on Reducing Sodium in Processed Foods; 2012. Available online: https://www.canada.ca/en/health-canada/services/food-nutrition/legislation-guidelines / guidance-documents / guidance-food-industry-reducing-sodium-processed-foods-2012.html (accessed on 1 December 2018).

23. Allemandi, L.; Tiscornia, M.V.; Ponce, M.; Castronuovo, L.; Dunford, E.; Schoj, V. Sodium content in processed foods in Argentina: Compliance with the national law. Cardiovasc. Diagn. Ther. 2015, 5, 197-206. [PubMed]

24. L'Abbé, M.R.; Schermel, A.; Arcand, J. Progress on sodium reduction in Canada and Latin America. Ann. Nutr. Metab. 2017, 71, 108-109.

25. Fitzpatrick, L.; Arcand, J.; L'Abbe, M.R.; Deng, M.; Duhaney, T.; Campbell, N.R.C. Canadian food labels: Are they accurate? Nutrients 2014, 6, 3326-3335. [CrossRef] [PubMed]

(C) 2019 by the authors. Licensee MDPI, Basel, Switzerland. This article is an open access article distributed under the terms and conditions of the Creative Commons Attribution (CC BY) license (http:// creativecommons.org/licenses/by/4.0/). 